\title{
TOXICIDADE DO LODO GERADO PELO TRATAMENTO BIOLÓGICO DA ÁGUA DE PRODUÇÃO, NO TERMINAL MARÍTIMO ALMIRANTE BARROSO, MUNICÍPIO DE SÃO SEBASTIÃO, SP
}

\section{R.C. Guerra; D.F. Angelis}

Universidade Estadual Paulista, Departamento de Bioquímica e Microbiologia, Av. 24A, 1515, CEP13506-900, Rio Claro, SP, Brasil. E-mail: guerra.ricardo@gmail.com

\section{RESUMO}

\begin{abstract}
A exploração dos campos produtores de petróleo tem como característica a extração de uma parcela deágua misturada ao óleo. Esta água deve ser separada do petróleo antes do processamento pelas refinarias, assim, originando um resíduo conhecido como Água de Produção (AP). Os sistemas projetados para o tratamento da AP empregam diferentes métodos, visando atingir maior eficiência na separação dos contaminantes da água. Entretanto, os processos de tratamento geram subprodutos que necessitam de posterior manuseio ou descarte. O presente trabalho tem como objetivo avaliar a toxicidade do produto de solubilização do lodo gerado pelo tratamento da AP em reatores aeróbios, proveniente da estação piloto de tratamento do efluente do Terminal Marítimo Almirante Barroso. Foram testadas as espécies: Barabarea verna Mill., Brassica oleracea L., Cucumis sativus L. e Eruca sativa Mill., quanto à porcentagem de germinação, velocidade média de germinação e inibição ao crescimento da raiz e hipocótilo. Os resultados indicam maior sensibilidade da germinação de B. verna ao extrato solubilizado, as demais espécies apresentaram concentração crítica para a germinação entorno de $25 \%$ do extrato solubilizado. A inibição ao crescimento da raiz e hipocótilo indica maior resistência das espécies E. sativa e B. oleracea, a concetração de inibição $\left(\mathrm{CI}_{50}\right)$ para essas espécies foi respectivamente de $23,61 \%$ e $16,64 \%$ para a raiz, para o hipocótilo a $\mathrm{CI}_{50}$ foi em torno de $18 \%$ para as duas espécies.
\end{abstract}

PALAVRAS-CHAVE: Salinidade, germinação, crescimento radicular, petróleo.

\section{ABSTRACT}

BIOLOGICALSLUDGE TOXICITY, FROMPRODUCEDWATER TREATMENT AT TERMINAL MARÍTIMO ALMIRANTE BARROSO, SÃO SEBASTIÃO, SÃO PAULOSTATE, BRAZIL. One of oil production characteristics is the mixed water volume co-produced. This water contain must be eliminated before refinery processing, originating a wastewater known as Produced Water. These waste treatment systems are designed by a combination of different methodologies, looking for greater treatment efficiency. In the mean time, treatment processes generate byproducts that need an ultimate disposal. This paper objective is to evaluate the solubilization product toxicity, from a biological sludge, produced at a Pilot Produced Water Treatment Facility, located on Terminal Marítimo Almirante Barroso. The species:Barabarea verna Mill., Brassica. oleraceaL., Cucumis. sativus L. and Eruca. sativa Mill., were used for bioassays tests based on germination percentage, germination velocity and root/hypocotyls elongation. Results indicate B. verna greater solubilization product germination sensibility, the remaining species showed a critical concentration of solubilization product about $25 \%$. The root/hypocotyls elongation tests indicate E. sativa and B. oleracea greater resistance, with root inibitory concentration $\left(\mathrm{IC}_{50}\right)$ of $23.61 \%$ and $16.64 \%$ respectively and, $\mathrm{IC}_{50}$ for hypocotyls about $18 \%$ for both species.

KEY WORDS: Salinity, germination, root elongation, petroleum.

\section{INTRODUÇÃO}

As atividades envolvidas na cadeia produtiva do petróleo desde sua extração, armazenamento, transporte e processamento para a produção de derivados, são responsáveis pela geração de diferentes tipos de resíduos. Estes são originários das impurezas presentes na composição natural do óleo ou provenientes de seu processamento (REBHUN;GALIL, 1994). Entre os resíduos gerados destaca-se, particularmente pelo volume envolvido, a água de produção. Esta pode ser definida como a parcela deágua que se separa doóleo 
durante o armazenamento, composta primariamente pela água de formação (naturalmente presente na formação geológica onde se realiza a prospecção do petróleo) e água de injeção, quando processos de recuperação secundária do petróleo são empregados (Holdway, 2002; HAYes; ArTHur, 2004).

Além dos compostos lixiviados das rochas reservatório, naturalmente presentes na água de formação, uma grande variedade de produtos químicos é adicionada durante o processamento do petróleo. Estes aditivos químicos são empregados para resolver ou prevenir problemas operacionais (BuRNs et al.,1999). A toxicidade aguda destes compostos químicos contribui para a toxicidade geral da Água de Produção (Holdway, 2002).

A maior parte das reservas brasileiras de petróleo encontra-se na Bacia de Campos, na margem continental dos Estados do Rio de Janeiro e Espírito Santo. A localização dos reservatórios em grandes profundidades (lâmina d'água superior a 2.000 m), contribui com o volume de água extraída junto ao petróleo, devidoà elevada pressão e percolação da água do mar através do meio sedimentar (CASSELLA et al., 2005).

O Terminal Marítimo de São Sebastião (TEBAR) é responsável pelo escoamento de aproximadamente $60 \%$ da produção nacional de petróleo para as refinarias localizadas no Estado de São Paulo. O óleo cru recebido pelo terminalé armazenado em tanques onde ocorre a separação óleo/água. A geração mensal de Água de Produção no TEBAR é entorno de $15.000 \mathrm{~m}^{3}$.

Os sistemas para o tratamento deste efluente são projetados com a combinação de diferentes metodologias de tratamento, visando atingir maior eficiência na separação e degradação dos contaminantes daágua. Entretanto, todos os processos com potencial aplicação no tratamento da Água de Produção geram subprodutos que necessitam de posterior processamento e descarte, de acordo com critérios de proteção ambiental e saúde pública.

O impacto ambiental provocado pelo descarte da água produzida, geralmente, é avaliado pela toxicidade dos constituintes e pela quantidade de compostos orgânicos e inorgânicos presentes. Estes contaminantes podem causar diferentes efeitos sobre o ambiente. Acredita-se que os efeitos mais nocivos são aqueles relacionados aos compostos que permanecem em solução após o descarte da água produzida (Oliveira; Oliveira, 2000).

Os organismos vivos incorporam tanto os efeitos positivos quanto negativos dos impactos químicos e condições ambientais vivenciadas durante seu desenvolvimento, fornecendo uma medida mais direta da toxicidade do que análises químicas isoladas (KEDDy etal.,1995). Desta forma, os testes de toxicidade representam uma ferramenta para o estudo dos efeitos de agentes tóxicos sobre organismos vivos, funda- mentando-se no princípio da resposta dos organismos ser proporcional à dose do tóxico a que foram submetidos (JARDIM, 2004).

Durante os estágios iniciais de desenvolvimento, as sementes são mais sensíveis ao estresse ambiental. Assim, os efeitos de agentes tóxicos podem ser monitorados por meio de endpoints como sobrevivência, germinação e estágios iniciais de desenvolvimento (BARBERo et al., 2001).

Os testes de toxicidade baseados na germinação de sementes e crescimento radicular têm sido propostos por diversas agencias governamentais, como parte da avaliação do potencial de contaminação de resíduos e efluentes dispostos no ambiente (OECD, 1984; USEPA, 1996).

O presente trabalho tem como objetivo avaliar o efeito tóxico da disposição do lodo gerado pela etapa de tratamento biológico da Água de Produção, proveniente de uma Estação Piloto de Tratamento de Efluentes (ETE piloto) instalada no TEBAR. A estação conta com três reatores biológicos aeróbios com biomassa em suspensão, operando em sistema de batelada seqüencial, delineados para a nitrificação/ desnitrificação da amônia. A produção de lodo é estimada entorno de $120 \mathrm{~kg} / \mathrm{h}$, retirado dos reatores com $4 \%$ de sólidos e, após processo de secagem, espera-se obter teor de sólidos em torno de $80 \%$.

Os ensaios de toxicidade foram realizados a partir da solubilização do lodo desidratado. O efeito de concentrações crescentes do extrato de solubilização do lodo, sobre a germinação e desenvolvimento inicial de plântulas de Barbarea verna Mill. (Agrião do seco), Brassica oleracea L. (Couve manteiga), Cucumis sativus L. (Pepino caipira) e Eruca sativa Mill. (Rúcula), foi avaliado como parte dos estudos sobre a disposição final deste resíduo e são apresentados neste trabalho.

\section{Metodologia}

Este trabalho foi realizado no Laboratório de ToxicidadedeÁguas daUniversidadeEstadualPaulista - Unesp, Campus de Rio Claro, SP. As sementes utilizadas na execução dos testes de germinação e de inibição docrescimento da raiz ehipocótilo foram adquiridas de ummesmofornecedor $\left(\right.$ TopSeed $^{\circledR}$ ). Noscasos ondemais de um lote de sementes foi necessário para a realização do teste, procedeu-se a homogeneização das sementes, com o objetivo de uniformizar a amostra.

\section{Caracterização do lodo}

Para melhor conhecimento das características do material estudado, o lodo coletado no reator de tratamento biológico da água de produção foi avaliado mediante parâmetros químicos, físicos e microbiológicos. Estes dados têm a intenção de apre- 
sentar um conjunto de informações gerais sobre o resíduo estudado.

A análise da Demanda Bioquímica de Oxigênio (DBO) e concentração de sólidos foram realizadas segundo CLESCERI et al. (1998). A determinação das bactérias heterotróficas foi realizada de acordo com CETESB (1978), a partir da observação dos tipos de colônias bacterianas encontradas, procedeu-se o isolamento e purificação da cultura em meio Plate Count Agar (PCA) contendo $50 \mathrm{~g} / \mathrm{L}$ de $\mathrm{NaCl}$.

\section{Desidratação do lodo}

A concentração e secagem do Lodo foram realizadas a partir do material coletado no ponto de descarga de lodo do reator biológico instalado no TEBAR. Para a concentração inicial do material, o lodo foi filtrado à vácuo, em seguida, a torta de lodo resultante foi desidratada em estufa a $45^{\circ} \mathrm{C}$ por um período de 48 horas. Mediante este procedimento uma concentração de sólidos compatível com a existente no projeto da ETE piloto foi obtida.

\section{Solubilização do lodo}

A obtenção do extrato solubilizado do lodo foi realizada a partir do lodo desidratado, segundo o método descrito pela Norma Técnica NBR 10.006 "Solubilização de resíduos - Procedimento" (ABNT, 2004a), como parte dos ensaios necessários à caracterização de resíduos sólidos.

Para a realização dos testes de germinação e inibição ao crescimento da raiz e hipocótilo, foram empregadas diluições doextrato solubilizado. Este material representa a fração do lodo desidratado sujeita à dissoluçãoemágua, desta forma, mais biodisponível. As soluções testadas variaram de 5 a $25 \%$ de concentração do extrato solubilizado, diluído em água desionizada. O tratamento controle era composto exclusivamente por água desionizada.

Tabela 1 - Valores de condutividade elétrica e potencial osmótico das diluições do extrato solubilizado, empregadas nos testes de germinação e inibição ao crescimento da raiz e hipocótilo.

\begin{tabular}{ccc}
\hline $\begin{array}{c}\text { Concentração extrato } \\
\text { solubilizado (v/v) }\end{array}$ & $\begin{array}{c}\text { Condutividade } \\
\text { elétrica }\left(\mathrm{dS} . \mathrm{m}^{-1}\right) \\
\text { a } 25^{\circ} \mathrm{C}\end{array}$ & $\begin{array}{c}\text { Potencial } \\
\text { osmótico } \\
(\mathrm{MPa})\end{array}$ \\
\hline $5 \%$ & 5,17 & $-0,19$ \\
$10 \%$ & 9,65 & $-0,35$ \\
$15 \%$ & 13,57 & $-0,50$ \\
$20 \%$ & 17,49 & $-0,64$ \\
$25 \%$ & 21,32 & $-0,78$ \\
\hline
\end{tabular}

A condutividade elétrica das diluições foi aferida em condutivimetro e, a partir dos valores obtidos calculou-se o potencial osmótico (Tabela 1) conforme FORSYTHE (1966), citado por SANTANA et al. (2003).

\section{Teste de germinação}

Para cada espécie vegetal foram testadas no mínimo cinco diluições do extrato solubilizado, em três repetições contendo 50 sementes. As sementes foram acondicionadas em placa de petri, sobre papel de filtro previamente esterilizado. A cada placa foi adicionado $4 \mathrm{~mL}$ da respectiva diluição testada e em seguida incubada em câmara climática (Estufa BOD) a $22 \pm 1^{\circ} \mathrm{C}$.

A contagem de sementes germinadas foi realizada em intervalos de 24 horas, considerando-se germinadas as sementes queapresentassem $2 \mathrm{~mm}$ de protrusão da radícula. A porcentagem total de sementes germinadas por tratamento foi calculada, assim como, a velocidade média de germinação, obtida por meio do inverso do tempo médio de germinação (LABOURIAU, 1983).

Os dados percentuais de germinação foram transformados para arco seno $(\% \mathrm{G}=\sqrt{\mathrm{x} / 100})$; a comparação entre as médias foi realizada pelo teste de Tukey, a $5 \%$ de probabilidade utilizando o software Biostat 4.0 (AYres et al., 2006).

\section{Teste de inibição da raiz e hipocótilo}

A realização dos testes de inibição da raiz e do hipocótilo seguiu os procedimentos descritos por Morales (2004). A partir dos resultados obtidos foi calculada a Concentração de Inibição de $50 \%\left(\mathrm{CI}_{50}\right)$ do conjunto de medidas da raiz e hipocótilo, em relação ao tratamento controle, para cada espécie vegetal.

\section{RESULTADOS E DISCUSSÃO}

\section{Caracterização do lodo}

A concentração de sólidos dissolvidos totais determinada para o lodo (Tabela 2), indica uma quantidade de sais pouco a cima da normalmente encontrada na água do mar, que apresenta em média $35 \mathrm{~g} / \mathrm{L}$ (WhitTen et al., 2004), resultando no alto valor de condutividade elétrica encontrado no lodo.

A Tabela 3 apresenta um grupo de seis bactérias isoladas a partir do lodo, as espécies compreendem cocos e bacilos, predominantemente gram positivos com variada pigmentação das colônias.

Aoperaçãodos reatores daestaçãopilotodoTEBAR não prevê a adição de inóculo microbiano. O desenvolvimento da biomassa ocorre a partir da própria 
população microbiana presente no efluente, mediante o fornecimento de uma fonte de carbono externa para estimular seu crescimento.

Tabela 2 - Resultado das análises do lodo biológico da ETEpiloto/TEBAR.

\begin{tabular}{lcl}
\hline Parâmetro & Valor & Unidade \\
\hline $\mathrm{pH}$ & 7,01 & - \\
Condutividade & 68,00 & $\mathrm{dS} \cdot \mathrm{m}^{-1}$ \\
$\mathrm{DBO}$ & 300,53 & $\mathrm{mgO}_{2} / \mathrm{L}$ \\
Sólidos dissolvidos totais & 38,00 & $\mathrm{~g} / \mathrm{L}$ \\
Sólidos suspensos totais & 25,05 & $\mathrm{~g} / \mathrm{L}$ \\
Sólidos suspensos voláteis & 15,61 & $\mathrm{~g} / \mathrm{L}$ \\
Bactérias heterotróficas & $1,48.10^{7}$ & $\mathrm{UFC}$ \\
\hline
\end{tabular}

A contagem de bactérias heterotróficas, da ordem de $1,48.10^{7} \mathrm{UFC}$, representa intensa atividade biológica do lodo, composto por microrganismos halotolerantes ou halófilos, adaptados às condições de salinidade do efluente em tratamento.

\section{Solubilização do lodo}

A análise química do extrato solubilizado do lodo demonstra que na composição deste resíduo a concentração dos elementos: sódio, chumbo, ferro, manganês, bário e cloreto, encontra-se acima dos limites máximos estabelecidos para o ensaio de solubilização (Tabela 4). Assim, de acordo com a Norma Técnica NBR 10.004 "Resíduos Sólidos Classificação" (ABNT, 2004b), este resíduo é classificado como: Classe II A, Não Perigoso - Não Inerte.

\section{Teste de germinação}

O resultado dos testes de germinação é apresentado pela Tabela 5. De maneira geral observa-se que, entre o potencial osmótico de - 0,5 e - $0,64 \mathrm{MPa}$, os efeitos deletérios do excesso de salinidade começam a causar diminuição significativa no percentual de germinação.
Entre as espécies testadas, B. verna demonstrou maior sensibilidade do processo de germinação ao aumento da concentração do extrato solubilizado. A partir do potencial osmótico de -0,35MPa é possível observar diferença significativa em relação ao tratamento controle, sendo o potencial de $-0,78 \mathrm{MPa}$ responsável pela inibição total da germinação.

Com exceção de $B$. verna, as outras espécies testadas apresentaram taxa de inibição da germinação acima de $50 \%$, apenas quando submetidas a $25 \%$ de concentração do extrato solubilizado $(-0,78 \mathrm{MPa})$.

A germinação de B. oleracea foi pouco afetada pelos potenciais osmóticos testados, sendo possível observar diferença significativa entre as diluições do extrato solubilizado, somente sob potencial osmótico de 0,78MPa. No intervalo entre 20 e $25 \%$ de concentração (-0,64 e -0,78MPa), observa-se diminuição de $33 \%$ na taxa de germinação de $B$. oleracea, indicando uma estreita faixa de pressão osmótica onde o ponto crítico em relação à capacidade de germinação é atingido.

A espécie C. sativus apresentou diminuição significativaemsuataxadegerminaçãosobpotencialosmótico de - $0,64 \mathrm{MPa}$, atingindo $75 \%$ de diminuição da taxa de germinação, em relação ao controle, quando submetida ao potencial osmótico de-0,78MPa. Torreset al.(2000) ao estudarem o efeito de diferentes concentrações salinas na germinação de $C$. sativus, encontraram diminuição da ordem de $36 \%$ sob potencial osmótico de -0,8MPa.

As sementes de E. sativa foram inibidas significativamente a partir do potencial osmótico de -0,5MPa. Sob potencial osmótico de - $0,78 \mathrm{MPaE}$. sativaapresentou porcentagem de germinação semelhante ao das espécies B. oleracea e C. sativus.

A Figura 1 apresenta os resultados obtidos para o cálculo da velocidade média de germinação das espécies testadas. Assim como os resultados obtidos para a porcentagem de germinação, o aumento da concentração do extrato solubilizado resultou em gradual diminuiçãoda velocidademédia degerminação. Desta forma, observa-sequeoaumento do potencial osmótico das diluições testadas, aumentou o intervalo de tempo entre a primeira e última observação de germinação, resultando no retardamento deste processo.

Tabela 3 - Caracterização das bactérias isoladas do lodo biológico da ETEpiloto/TEBAR.

\begin{tabular}{|c|c|c|c|c|}
\hline Morfologia celular & Coloração das colônias & Parede celular & Endosporos & $\mathrm{EPS}^{*}$ \\
\hline$\overline{\mathrm{Coco}}$ & Laranja Claro & Gram + & - & + \\
\hline Coco & Creme Escuro & Gram + & + & + \\
\hline Coco & Laranja Brilhante & Gram - & - & - \\
\hline Tetrade & Amarelo Claro & Gram + & - & - \\
\hline Bacilo & Creme Claro & Gram + & - & - \\
\hline Bacilo Curto & Creme Claro & Gram - & - & - \\
\hline
\end{tabular}

*Produção de exopolissacarídeos. 
Tabela 4 - Análises químicas do extrato solubilizado (mg.L $\left.\mathrm{L}^{-1}\right)$, do lodo biológico da ETEpiloto/TEBAR.

\begin{tabular}{|c|c|c|}
\hline Elementos químicos & Solubilização & $\mathrm{LM}^{1}$ \\
\hline Sódio & 10,400 & 200,0 \\
\hline Potássio & 369,0 & * \\
\hline Silício & 4,4 & * \\
\hline Cálcio & 1.583 & * \\
\hline Estrôncio & 112,0 & * \\
\hline Magnésio & 478,0 & * \\
\hline Chumbo & 0,28 & 0,01 \\
\hline Ferro & 0,79 & 0,3 \\
\hline Manganês & 0,74 & 0,1 \\
\hline Cromo total & $<0,05$ & 0,05 \\
\hline Fósforo & 4,6 & * \\
\hline Alumínio & $<0,1$ & 0,2 \\
\hline Zinco & 0,026 & 5,0 \\
\hline Bário & 4,02 & 0,7 \\
\hline Níquel & 0,021 & * \\
\hline Boro & 10,02 & * \\
\hline Prata & $<0,1$ & 0,05 \\
\hline Cobre & $<0,008$ & 1,0 \\
\hline Sulfato & 270,0 & 400,0 \\
\hline Cloreto & 23.000 & 250,0 \\
\hline Cádmio & $<0,005$ & 0,005 \\
\hline
\end{tabular}

LM - Limite Máximo Permissível para o Ensaio de Solubilização;

*elementos químicos não considerados pela NBR 10.004 (Anexo G).

De maneira geral, à medida que aumentam as concentrações de sais no meio, observa-se a necessidade de mais tempo para a semente intumescer e germinar, logo, há uma menor velocidade de germinação (NóBREGA et al., 1999; Rosa et al., 2005).

A comparação entre os resultados de porcentagem evelocidade média degerminação, demonstraaimportância deste ultimo parâmetro para a obtenção de uma melhor avaliação do comportamento das espécies durante o processo de germinação. Observa-se para a espécie C. sativus que, mesmo em concentrações onde a taxa de germinaçãonão diferiu do controle, permanecendo entorno de $100 \%$, uma diminuição da velocidade média de germinação foi evidente. Comportamento semelhante pôde ser observado para a germinação de B. oleracea, entretanto com diminuição da velocidade média de germinação menos pronunciada.

\section{Teste de inibição da radícula e hipocótilo}

As Figuras 2 e 3 apresentam a regressão linear resultante do teste de inibição ao crescimento da raiz e hipocótilo. O conjunto de dados, para as quatro espécies testadas, a presentou um coeficiente de determinação $\left(R^{2}\right)$ entre 93 e $99 \%$, indicando um alto grau de correlação entre os dados obtidos experimentalmente e os valores de inibição calculados para a determinação da $\mathrm{CI}_{50}$.

Os valores obtidos no tratamento controle para o comprimento da raiz de $B$. verna apresentaram média de $18,30 \mathrm{~mm}$, com intervalo de confiança (IC95\%) entre 16,45 e $19,85 \mathrm{~mm}$, para o comprimento do hipocótilo, média de 22,93 $\mathrm{mm}$ (IC95\% = 21,55 a 24,32 $\mathrm{mm})$. Os valores calculados de $\mathrm{CI}_{50}$ para a raiz e hipocótilo de $B$. verna apresentaram variação entre 13,13 e 10,18\% de concentração do extrato solubilizado.

O tratamento controle de B. oleracea, para o comprimento da raiz, apresentou média de $42,38 \mathrm{~mm}$ (IC95\% $=40,27$ a 44,22 mm), o comprimento do hipocótilo foi em média 24,09 mm (IC95\% = 22,70 a 25,26 mm) Os valores de $\mathrm{CI}_{50}$ calculados para a inibição da raiz e hipocótilo de $B$. oleracea apresentaram variação entre 16,64 e18,18\% deconcentração do extrato solubilizado.

A média encontrada para o comprimento das raízes de $C$. sativus, no tratamento controle, foi de $70,36 \mathrm{~mm}$ (IC95\% = 67,57 a 72,68mm), o comprimento médio do hipocótilo foi de 28,62 $\mathrm{mm}$ (IC95\% = 27,60 a $29,50 \mathrm{~mm}$ ), os valores de $\mathrm{CI}_{50}$ calculados para a inibição da raiz e hipocótilo de C. sativus variaram entre 11,27 e $11,69 \%$ de concentração do extrato solubilizado.

Tabela 5 - Porcentagem média de germinação para as espécies testadas, submetidas à concentrações crescentes do extrato solubilizado do lodo biológico, produzido pelo tratamento da água de produção pela ETEpiloto/TEBAR.

\begin{tabular}{|c|c|c|c|c|c|c|}
\hline \multirow[t]{3}{*}{ Espécie } & \multicolumn{6}{|c|}{ Potencial osmótico } \\
\hline & Controle & - 0,19MPa & $-0,35 \mathrm{MPa}$ & - 0,50MPa & $-0,64 \mathrm{MPa}$ & $-0,78 \mathrm{MPa}$ \\
\hline & \multicolumn{6}{|c|}{ Germinação (\%) } \\
\hline B. verna & 96,6 aA & $92,2 \mathrm{aA}$ & $53,3 \mathrm{bA}$ & 17,8 cA & $4,4 \mathrm{dA}$ & $0,0 \mathrm{eA}$ \\
\hline B. oleracea & 97,8 aA & $95,4 \mathrm{aA}$ & $92,2 \mathrm{aB}$ & $77,8 \mathrm{aB}$ & $80,0 \mathrm{aB}$ & $46,7 \mathrm{bB}$ \\
\hline C. satious & $100 \mathrm{aA}$ & $100 \mathrm{aA}$ & $100 \mathrm{aB}$ & $98,3 \mathrm{aB}$ & $63,3 \mathrm{bB}$ & $25,0 \mathrm{cC}$ \\
\hline E. sativa & $98,9 \mathrm{aA}$ & $96,7 \mathrm{aA}$ & $86,7 \mathrm{abB}$ & $78,3 \mathrm{bB}$ & $73,3 \mathrm{bB}$ & $33,3 \mathrm{cBC}$ \\
\hline
\end{tabular}

Médias seguidas das mesmas letras, maiúscula para coluna e minúscula para linha, não diferem pelo teste de Tukey, em nível de $5 \%$ de probabilidade. 


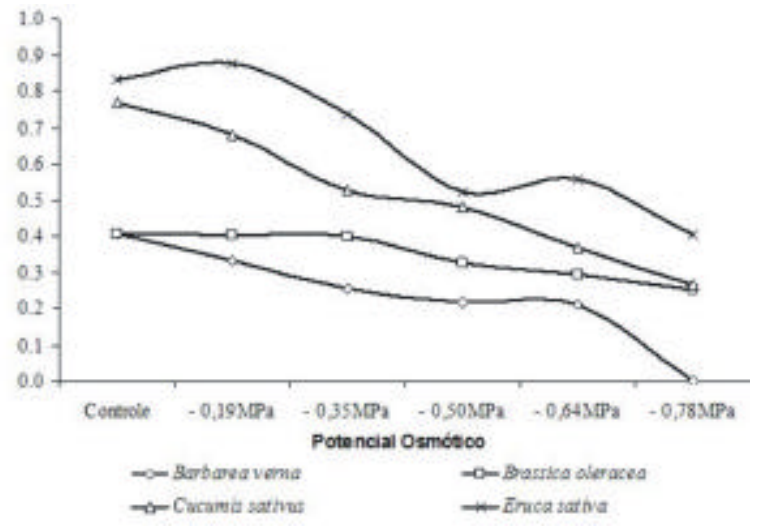

Fig. 1 - Velocidade média de germinação das espécies submetidas ao extrato solubilizado do lodo biológico, produzido pelo tratamento da água de produção na ETEpiloto/TEBAR.

Os valores obtidos no tratamento controle para o comprimento da raiz deE. sativa, apresentarammédia de 37,25 mm (IC95\% = 34,50 a 40,06 mm), o comprimento do hipocótilo foi em média 30,98 mm (IC95\% $=29,52$ a 32,31 mm). E. sativa diferiu do padrão encontrado para as outras espécies testadas, apresentando maior variação entre o valor calculado da $\mathrm{CI}_{50}$ para a raiz e hipocótilo, $23,61 \%$ e $18,45 \%$, respectivamente.

Os testes de germinação e inibição ao crescimento para a espécie B. verna, apresentaram resultados com comportamento semelhante. Frente ao aumento da concentração do extrato solubilizado, os dois testes indicaram inibição de $50 \%$ da amostra em torno de $10 \%$ de concentração.

As espécies B. oleracea e E. sativa não sofreram efeitos pronunciados sobre a porcentagem de germinação até a faixa de concentração compreendida entre 20 e $25 \%$ deconcentração do extrato solubilizado (-0,64 e-0,78 MPa, respectivamente). As duas espécies também demonstraram maior resistência à inibição do crescimento pelo extrato solubilizado.
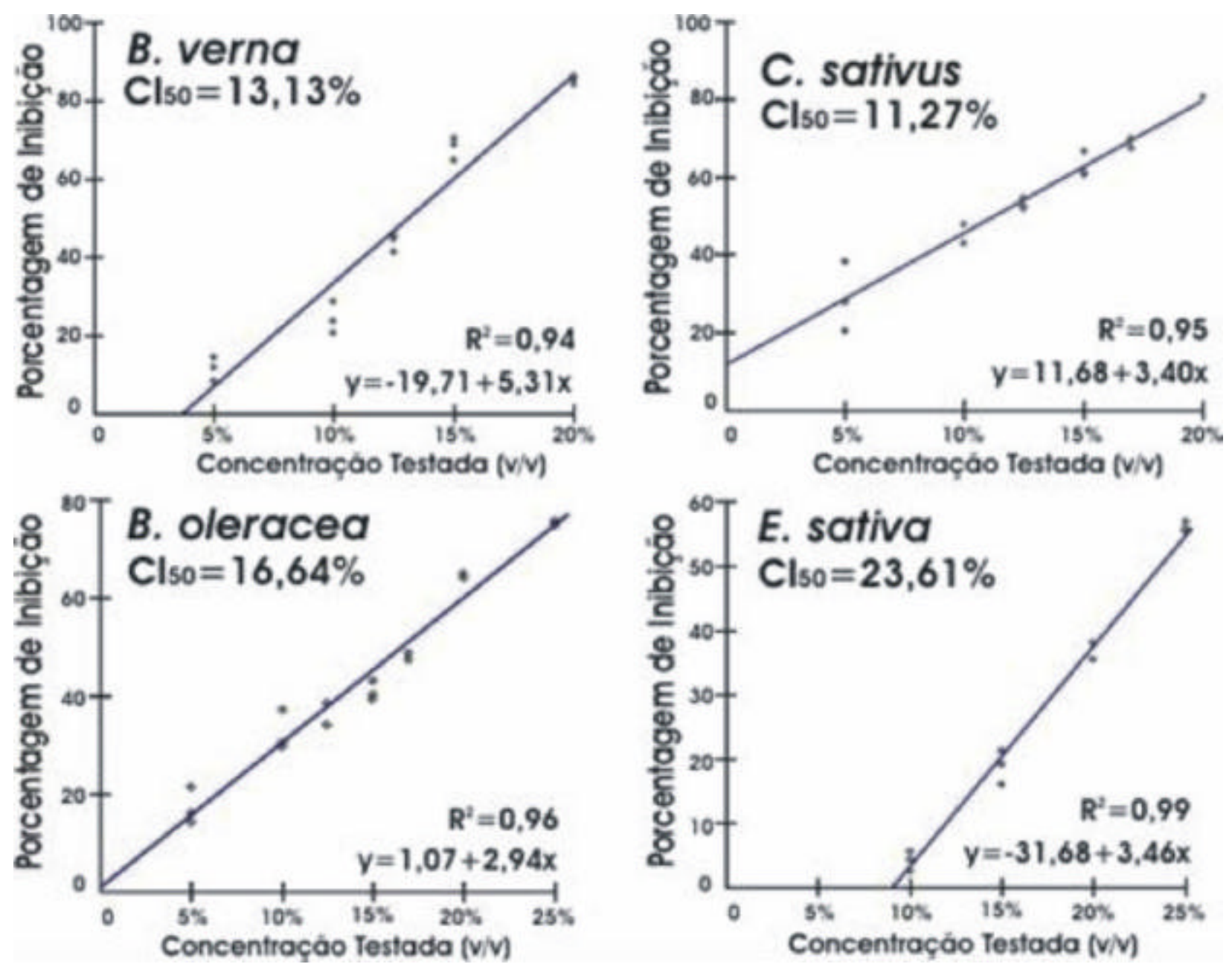

Fig. 2 - Regressão linear da porcentagem média de inibição do crescimento da raiz, em relação ao tratamento controle, das espécies testadas sob concentrações crescentes do extrato solubilizado do lodo biológico, produzido pelo tratamento da água de produção pela ETEpiloto/TEBAR. 

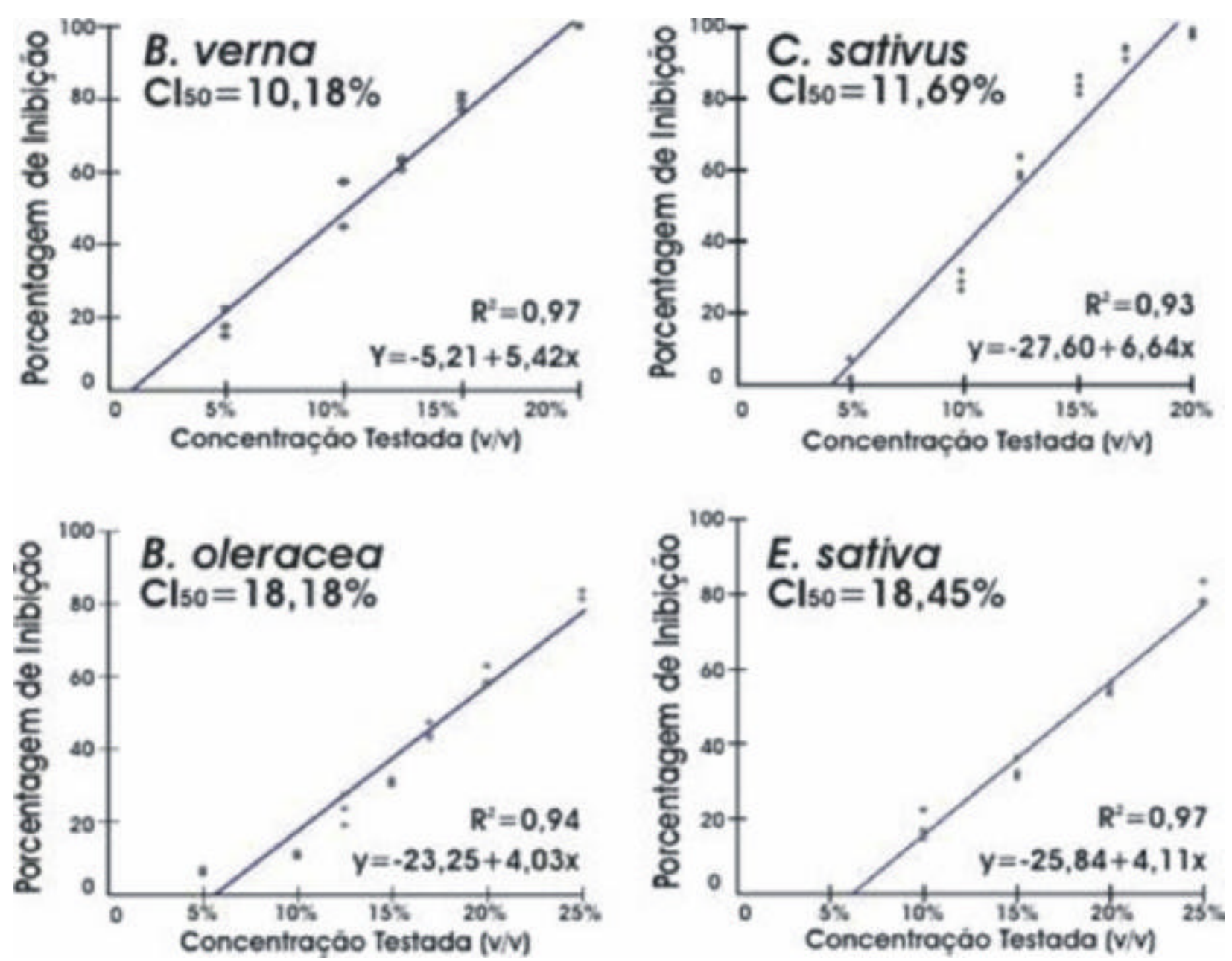

Fig. 3 - Regressão linear da porcentagem média de inibição do crescimento do hipocótilo, em relação ao tratamento controle, das espécies testadas sob concentrações crescentes do extrato solubilizado do lodo biológico, produzido pelo tratamento da água de produção pela ETEpiloto/TEBAR.

A diminuição da porcentagem de germinação de sementes submetidas ao estresse hídrico pode ser atribuída à redução das atividades enzimáticas (LABOURIAU, 1983). Segundo Machado et al. (2006) o potencial osmótico de soluções salinas pode atingir valores inferiores aos apresentados pelas células do embrião, dessa maneira, dificultando a absorção da água necessária para que a germinação seja possível. SANTOs et al. (1992) sugeriram que os efeitos tóxicos da salinidade sobre a germinação, ocorram não somente por dificultar a cinética da absorção de água, mas também por facilitar a entrada de íons em quantidades tóxicas nas sementes durante a embebição, sendo constatado que os efeitos provocados pelos sais são mais nocivos à germinação do que apenas o efeito osmótico.

Segundo Harris (1915) citado por CAMPOS; AssunÇão (1990), o grau de toxicidade de sais solúveis para a germinação de trigo, milho, beterraba, alfafa, aveia e cevada apresentou a seguinte ordem: $\mathrm{NaCl}>\mathrm{CaCl}_{2}$ $>\mathrm{KCl}>\mathrm{NaNO}_{3}>\mathrm{MgCl}_{2}>\mathrm{KNO}_{3}>\mathrm{MgNO}_{3}>\mathrm{Na}_{2} \mathrm{CO}_{3}$
$>\mathrm{K}_{2} \mathrm{CO}_{3}>\mathrm{Na}_{2} \mathrm{SO}_{4}>\mathrm{K}_{2} \mathrm{SO}_{4}>\mathrm{MgSO}_{4}$.

$\mathrm{O}$ efeito tóxico observado nos testes realizados pode não estar exclusivamente relacionado ao potencial osmótico a que as sementes foram expostas. A condutividade elétrica das soluções testadas (Tabela 1) era devida aos sais presentes na água do mar, concentrados pela desidratação térmica do lodo. Entretanto, outros contaminantes provenientes da formação geológica ou contato da água com frações mais solúveis do petróleo foram encontrados pela análise química do extrato solubilizado, indicando que estes elementos podem ter contribuído para um maior efeito tóxico sobre as espécies vegetais testadas.

\section{CONCLUSÃO}

O lodo produzido pelo reator da ETE piloto do TEBAR é classificado como um resíduo não perigoso, porém não inerte, devido à solubilização de alta concentração de sais e metais como: chumbo, ferro, 
manganês e bário. Desta forma, dado o potencial de contaminação do resíduo, sua disposição final demanda medidas adequadas de proteção ambiental.

Apesar da alta concentração de bactérias heterotróficas encontrada no lodo, uma baixa diversidade dos tipos celulares foi observada.

No teste de germinação, com exceção da espécie $B$. verna, o efeito letal foi mais evidente somente sob a concentração de $25 \%$ do extrato solubilizado dolodo.

A velocidade média de germinação, para todas as espécies, foi diminuida em resposta ao aumento das concentrações testadas.

O teste de crescimento da raiz e hipocótilo apresentou o efeito inibitório de forma mais gradual, para níveis sub-letais de concentração do extrato solubilizado.

A associação de testes quantitativos (\% de germinação) e qualitativos (crescimento) ofereceu um melhor conjunto de informações, ampliando as possibilidades de interpretação dos resultados.

\section{AGRADECIMENTOS}

Ao Programa de Formação de Recursos Humanos para a Indústria de Petóleo e Gás PRH-05, pelo financiamento do projeto; ao Depto de Bioquímica e Microbiologia da UNESP/Rio Claro; à Divisão de Biotecnologia e Tratamento Ambientais (BTA) do Centro de Pesquisas da Petrobrás (CENPES); ao pessoal de SMS e Tratamento de Resíduos do TEBAR.

\section{REFERÊNCIAS}

ABNT - Associação Brasileira de Normas Técnicas. NBR - 10.006 Solubilização de Resíduos, 2p. 2004(a).

ABNT - Associação Brasileira de Normas Técnicas. NBR - 10.004 Resíduos Sólidos - Classificação, 33p. 2004(b).

AYRES, M.; AYRES JUNIOR, M.; AYRES, D. L.; SANTOS, A. S. Bio Estat 4.0: aplicações estatísticas nas áreas de ciências biológicas e médicas. Belém: Sociedade Civil Mamirauá, 2006.

BARBERO, P.; BELTRAMI, M.; BAUDO, R.; ROSSI, D. Assessment of Lake Orta sediments phytotoxicity after the liming treatment. J. Limnol. v.60, n.2, p.269-276, 2001.

BURNS, K.A.; CODI, S.; FURNAS, M.; HEGGIE, D.; HOLDWAY, D.; KING, B.; MCALLISTER, F. Dispersion and fate of produced formation water constituents in an australian northwest shelf shallow water ecosystem. Marine Pollution Bulletin. v.38, n.7, p.593-603, 1999.
CAMPOS, I.S.; ASSUNÇÃO, M.V. Efeitos do cloreto de sódio na germinação e vigor de plântulas de arroz. Pesquisa Agropecuária Brasileira, Brasília, v.25, n.6, p.837843,1990 .

CASSELLA, R.J.;OLIVEIRA, E.P.; MAGALHÃES O.I.B. Direct determination of vanadium in high saline produced waters from offshore petroleum exploration by electrothermal atomic absorption spectrometry. Talanta. 2005. Disponível em: <http//www.elsevier. com/locate/talanta >. Acesso em: 5 fev. 2006.

CETESB - Companhia de Tecnologia e Saneamento Ambiental. Contagem Padrão de Colônias de Bactérias L5.201. São Paulo, CETESB, 1978. 11p.

CLESCERI, L.S.; GREENBERG, A.E.; EATON, A.D. (Ed.). Standard methods for examination of water and wastewater. 20thed. Baltimore: United Book Press, 1998.

HAYES, T.; ARTHUR, D. Overview of emerging produced water treatment technologies. In: ANNUAL INTERNATIONAL PETROLEUM ENVIRONMENTAL CONFERENCE, 11, 2004, Albuquerque, Proceeding. Albuquerque, 2004.

HOLDWAY, D.A. The acute and chronic effects of wastes associated with offshore oil and gas production on temperate and tropical marine ecological processes. Marine Pollution Bulletin, v.44, p.185-203, 2002.

JARDIM, G.M. Estudos ecotóxicológicos da água e do sedimento do Rio Corumbataí, SP. 2004. 138p. Dissertação (Mestrado em Ecologia de Agroecossistemas) - Universidade de São Paulo, Escola Superior de Agricultura "Luiz de Queiroz"; Piracicaba, 2004.

KEDDY, C.J.; GREENE, J.C.; BONNELL, M.A. Review of whole-organism bioassays: soil, freshwater sediment, and freshwater assessment in Canada. Ecotoxicology and Environmental Safety, v.30, p.221-251, 1995.

LABOURIAU, L.G. A germinação das sementes. Washington: OEA: 174p, 1983.

MACHADO, N.B.N.; CUSTÓDIO, C.C.; COSTA, P.R.; DONA, F.L. Deficiência hídrica induzida por diferentes agentes osmóticos na germinação e vigor de sementes de feijão. Revista Brasileira de Sementes, v.28, n.1, p.142148,2006

MORALES, C.G. Ensayos toxicológicos y métodos de evaluación de calidad de agua: estandarización, intercalibración, resultados y aplicaciones. Cidade do México: IMTA, 2004. 142p.

NOBREGA, G.M.N.; QUEIROZ, J.E.; SILVA, L.M.M.; SANTOS, R. V. Efeito da salinidade na germinação e desenvolvimento inicial da Leucena. Revista Brasileira de Engenharia Agrícola e Ambiental, v.3, n.2, p.257-260, 1999. 
OECD. Terrestrial plants: Growth test. OECD Guidelines for testing of chemicals, Paris: OECD, 1984.

OLIVEIRA, R.C.G.; OLIVEIRA, M.C.K. Remoção de contaminantes tóxicos dos efluentes líquidos oriundos da atividade de produção de petróleo no mar. Boletim Técnico da Petrobras, v.43, n.2, p.129-136, 2000.

REBHUN, M.; GALIL, N. Technological strategies for protecting and improving the biological treatment of wastewater from a petrochemical complex. Water Science and Technology, v.29, n.9, p.133-141, 1994.

ROSA, L.S.; FELIPPI, M.; NOGUEIRA, A.C.; GROSSI, F. Avaliação da germinação sob diferentes potenciais osmóticos e caracterização morfológica da semente e plântula de Ateleia glazioviana Baill (Timbó). Cerne, v.11, n.3, p.306-314, 2005.

SANTANA, M.J.; CARVALHO, J.A.; SILVA, E.L.; MIGUEL, D.S. Efeito da irrigação com água salina em um solo cultivado com o feijoeiro (Phaseolus vulgaris L.). Ciência e Agrotecnologia, v.27, n.2, p.443-450, 2003.
SANTOS, V.L.M.; CALIL, A.C.; RUIZ, H.A.; ALVARENGA, E.M.; SANTOS, C.M. Efeito do estresse salino e hídrico na germinação e vigor de sementes de soja. Revista Brasileira de Sementes, v.14, n.2, p.189-194, 1992.

TORRES, S. B.; VIEIRA, E. L.; MARCOS FILHO, J.

Efeitos da salinidade na germinação e no desenvolvimento de plântulas de pepino. Revista Brasileira de Sementes, v.22, n.2, p.39-44, 2000.

USEPA Ecological effects test guidelines. OPPTS 850.4200. Seed Germination/Root Elongation Toxicity Test. EPA 712-C-96-154. april 1996.

WHITTEN, K.W.; GAILEY, K.D.; DAVIS, R.E. General chemistry with quantitative analysis. 7.ed. Philadelphia: Saunders College Publishing, 2004. p.1232.

Recebido em 13/07/07

Aceito em 09/02/09 